\title{
Upregulation of hyaluronan-mediated motility receptor in hepatocellular carcinoma predicts poor survival
}

\author{
XIAOHU HE ${ }^{1,2^{*}}$, WEIJIA LIAO ${ }^{2,3^{*}}$, YULAN LI ${ }^{3}$, YONGQIN WANG ${ }^{2,3}$, QIAN CHEN ${ }^{1,2}$, \\ JUNFEI JIN ${ }^{2,3}$ and SONGQING $\mathrm{HE}^{2,3}$ \\ ${ }^{1}$ Department of Hepatobiliary and Pancreatic Surgery; \\ ${ }^{2}$ Laboratory of Hepatobiliary and Pancreatic Surgery, The Affiliated Hospital of Guilin Medical University; \\ ${ }^{3}$ Guangxi Key Laboratory of Molecular Medicine in Liver Injury and Repair, Guilin, Guangxi 541001, P.R. China
}

Received November 8, 2014; Accepted September 15, 2015

DOI: $10.3892 / 01.2015 .3773$

\begin{abstract}
Hepatocellular carcinoma (HCC) is one of the most common types of cancer across the world. Hyaluronic acid (HA) has been reported to serve an important role in tumor extension, progression, migration and invasion. In addition, the receptor for HA-mediated motility (RHAMM) has been demonstrated to be overexpressed in different types of cancer. However, whether the upregulation of RHAMM contributes to hepatocarcinogenesis of HCC remains unclear. The present study examined the RHAMM expression in 187 HCC patients by reverse transcription-quantitative polymerase chain reaction (RT-qPCR) and immunohistochemistry (IHC). RHAMM expression was significantly upregulated in liver cancer tissues compared with that observed in adjacent normal liver tissues. The IHC analysis demonstrated that RHAMM was overexpressed in $18(72.0 \%)$ of the 25 HCC tissues. Furthermore, overexpression of RHAMM was associated with tumor-node-metastasis (TNM), the presence of vascular invasion and recurrence. Notably, the present study indicated that the overexpression of RHAMM was closely associated with the shorter disease-free and overall survival, so it may be a potential independent predictor for disease-free and overall survival of HCC patients. In conclusion, the upregulation of RHAMM is associated with HCC progression and prognosis; and it may be a potential independent predictor of disease-free and overall survival of HCC following surgical resection.
\end{abstract}

Correspondence to: Dr Junfei Jin or Dr Songqing He, Laboratory of Hepatobiliary and Pancreatic Surgery, The Affiliated Hospital of Guilin Medical University, 15 Lequn Road, Guilin, Guangxi 541001, P.R. China

E-mail: changliangzijin@163.com

E-mail: dr_hesongqing@163.com

*Contributed equally

Key words: receptor for hyaluronic acid-mediated motility, hyaluronic acid, hepatocellular carcinoma

\section{Introduction}

Liver cancer is one of the most common neoplasms worldwide, and hepatocellular carcinoma (HCC) is the most prevalent type of liver cancer and accounts for $70-85 \%$ of all cases (1), ranking the sixth most common malignant tumors worldwide (2). More than 600,000 people lose their lives due to HCC every year (3), and HCC is the third most frequent cause of cancer-associated mortality (4). Previous studies have demonstrated that the incidence rate of HCC has been increasing. Surgical resection and liver-transplantation are superior therapeutic methods for HCC compared with other treatments, including radiofrequency ablation (RFA), transarterial chemoembolization (TACE) and chemotherapy, the treatment outcomes remain unsatisfactory owing to the high recurrence rate and high fatality rate of HCC (2). If HCC was detected and diagnosed earlier, surgical resection and liver-transplantation would result in an improved curative effect, therefore improving the disease-free and overall survival. The serum levels of $\alpha$-fetoprotein (AFP) and ultrasonography (US) are widely used to screen for and assess HCC throughout the world. However, the sensitivity and specificity of AFP for HCC diagnosis and surveillance have certain limitations; US depends on the operator's skill, and clinicians are not always able to distinguish HCC clearly from other nodules (5). Consequently, novel potential serum biomarkers are required for prognosis and metastatic recurrence of HCC.

Hyaluronic acid (HA) is an extracellular matrix (ECM) polymer and is frequently localized in the stroma of solid tumors, which is synthesized by stromal fibroblasts in response to paracrine factors produced by tumor cells (6). HA serves an important role in cellular events, including cell migration, gene expression, signaling, proliferation, motility, adhesion, metastasis and morphogenesis $(7,8)$.

The receptor for HA-mediated motility (RHAMM, also known as CD168), which is an HA-binding protein, is located in different parts of cell with different functions. For example, when RHAMM combines with hyaluronan on the cell surface, it can activate a signal transduction cascade to cause intracellular protein tyrosine phosphorylation. In addition, it also locates in the cytoplasm, centrosome, the cytoskeleton and nucleus (9). It can also interact with microtubules and actin filaments, mitotic 
spindle assembly, which is important to the organization of cytoskeletal network (10). RHAMM is not only a modulator of growth factor receptor, but also has major roles in progression and proliferation of various types of cancer $(9,11)$. RHAMM has been found in a variety of mammalian cells, including smooth muscle cells, endothelial cells, nerve cells, macrophages, spermatozoa $(12,13)$, and certain types of tumor cell, including prostate (14), breast (15) and gastric (16) cancer, and B-cell chronic lymphocytic leukemia (17). However, whether the upregulation of RHAMM contributes to hepatocarcinogenesis of HCC remains unclear. In the present study, it was demonstrated that RHAMM was frequently upregulated in HCC and its upregulation was closely associated with shorter disease-free and overall survival of HCC patients.

\section{Materials and methods}

Patient specimens. A total of 187 HCC cancer patients who underwent surgical resection at the Affiliated Hospital of Guilin Medical University (Guilin, China) between November 2001 and April 2007 were enrolled in the present study. The patients were diagnosed by the clinical symptoms, serological tests, US, computed tomography (CT) scans, magnetic resonance imaging (MRI), and pathological evaluations according to the 'Primary Liver Cancer Clinical Diagnosis and Staging Criteria' (18). The clinicopathological characteristics for these patients, including age, gender, family history, hepatitis B surface antigen (HBsAg), AFP level, median size and number, presence of combined liver cirrhosis, vascular invasion, history of alcohol consumption, presence of distant metastasis, tumor-node-metastasis (TNM), lymph node metastasis (LNM) and incidence of postoperative recurrence, are presented in Table I. In addition, 10 specimens of normal liver tissues adjacent to the hepatic hemangioma tissues were also collected. Following the surgery, all the normal tissues were examined by pathological examination. All of the samples were immediately frozen in liquid nitrogen and then stored at $-80^{\circ} \mathrm{C}$ following the surgical resections. The present study was approved by the Ethics Committee of the Affiliated Hospital of Guilin Medical University. All patients provided written informed consent to participate in this study according to the Declaration of Helsinki.

The HCC patients were followed-up following surgery by monitoring their serum AFP levels and performing US every 2 months and chest radiography every 6 months during the first 2 postoperative years and at 3-6 months intervals thereafter. A CT scan or MRI was performed if recurrence was suspected based on a rising of AFP level or abnormal US. Disease-free survival was measured from the day of surgery to the date of recurrence, metastasis, mortality or last follow-up. And overall survival was measured from the day of surgery to the date of death or last follow-up.

RNA extraction and cDNA synthesis. Total RNA was extracted from the frozen HCC tissue samples using TRIzol reagent (Invitrogen, Carlsbad, CA, USA). To reduce the risk of genomic DNA contamination, 1-2 $\mu \mathrm{g}$ RNA was incubated with $2 \mu$ l DNase I (Invitrogen), $1 \mu$ l DNase buffer and $0.4 \mu 1$ RNase out for $15 \mathrm{~min}$ at room temperature. The RNA concentration was determined by spectrophotometry (170-2525, Bio-Rad
Laboratories, Inc., Hercules, CA, USA), and total RNA integrity was examined by visualization of the $28 \mathrm{~S}$ and $18 \mathrm{~S}$ ribosomal RNAs on a $1.2 \%$ agarose gel. First-strand cDNA was synthesized using the Prime Script RT reagent kit (Takara Bio, Inc., Otsu, Japan) according to the manufacturer's instructions.

Reverse transcription-quantitative polymerase chain reaction (RT-PCR). RT-qPCR analysis was performed using SYBR Premix Ex Taq (Takara Bio, Inc., Otsu, Japan) according to the manufacturer's instructions. The primer sequences for RHAMM (Invitrogen) were as follows: F 5'-CAGCTG GAAGATGAAGAAGGA-3' and R 5'-GCATGTAGTTGT AGCTGAAAAGG-3', and the length of the amplicon was 137 bp. $\beta$-actin was used as the internal reference, with the primer sequences (Invitrogen) designed as follows: F 5'-GAC AGGATGCAGAAGGAGATTACT-3' and R 5'-TGATCC ACATCTGCTGGAAGGT-3', and the length of the amplicon was 142 bp. RT-qPCR amplification and data analysis were performed using the ABI Prism 7500 Sequence Detector system (Applied Biosystems, Foster City, CA, USA). Each cDNA sample was mixed with $15 \mu \mathrm{l}$ SYBR-Green PCR Master Mix (Applied Biosystems). The thermal profile for the PCR reaction consisted of an initial denaturation step at $95^{\circ} \mathrm{C}$ for $10 \mathrm{~min}$, then 35 cycles of denaturation at $95^{\circ} \mathrm{C}$ for $30 \mathrm{sec}$, annealing at $55^{\circ} \mathrm{C}$ for $30 \mathrm{sec}$, followed by extension at $72^{\circ} \mathrm{C}$ for $30 \mathrm{sec}$, and fluorescence acquisition at $72^{\circ} \mathrm{C}$. The mean $\mathrm{Ct}$ value for $\beta$-actin was subtracted from the mean $\mathrm{Ct}$ value for RHAMM in each sample using the following formula: RHAMM $\Delta C t=($ mean RHAMM Ct - mean $\beta$-actin $\mathrm{Ct})$. The fold-change $\left(2^{\text {-RHAMM } \Delta \Delta \mathrm{Ct}}\right)$ of the RHAMM expression level relative to the $\beta$-actin expression level was calculated for each sample (19).

Immunohistochemistry (IHC) assay. The formalin-fixed, paraffin-embedded tissue blocks were overlaid with the corresponding hematoxylin-eosin (H\&E)-stained slides for tissue microarray sampling. These tissue array slides (HCC and ANLT) were reviewed by 2 histopathologists, and representative tumor areas that were free form necrotic and hemorrhagic materials were pre-marked in the paraffin blocks. These tissue microarray slides were de-waxed with xylene (Sigma-Aldrich, St. Louis, MO, USA), rehydrated in graded ethanol (Sigma-Aldrich), antigen-retrieved by pressure cooking for $3 \mathrm{~min}$ in ethylenediaminetetraacetic acid (EDTA) buffer (pH 8.0; Sigma-Aldrich), and washed in phosphate-buffered saline (PBS; Sigma-Aldrich) 3 times (each wash was $3 \mathrm{~min}$ ). The slides were then immersed in $3 \%$ hydrogen peroxide (Sigma-Aldrich) for $10 \mathrm{~min}$ to block endogenous peroxidase activity and pre-incubated with $10 \%$ normal goat serum (Cayman Chemical Co., Ann Arbor, MI, USA) at room temperature for $30 \mathrm{~min}$ to reduce nonspecific reaction. Subsequently, the slides were incubated with a mouse polyclonal anti-RHAMM antibody (catalog no. GR31505-2, 1:200 dilution; Abcam, Cambridge, UK) at $4^{\circ} \mathrm{C}$ in a moist chamber overnight, and then washed with PBS, incubated with a biotinylated goat anti-mouse antibody (dilution, 1:2000; cat. no. ab97218, Abcam, Cambridge, UK) for $1 \mathrm{~h}$, and stained with 3,3'-diaminobenzidine tetrahydrochloride (DAB; Sigma-Aldrich) at room temperature. The slides were 
A

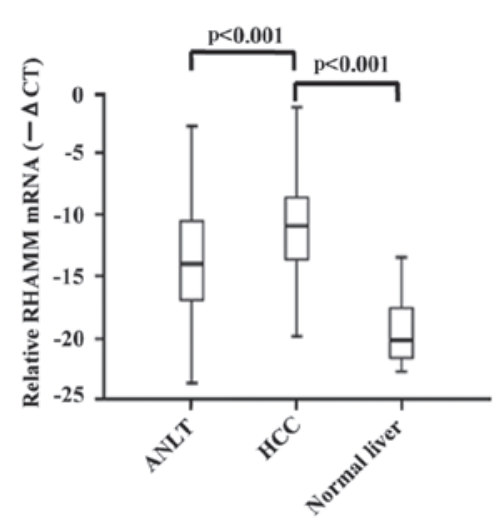

B

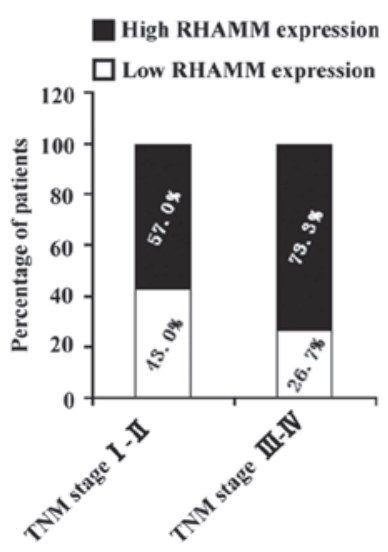

C

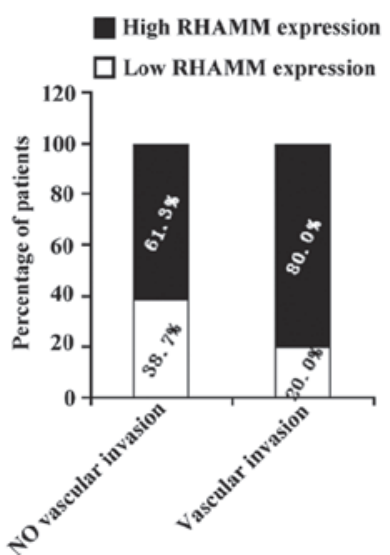

D

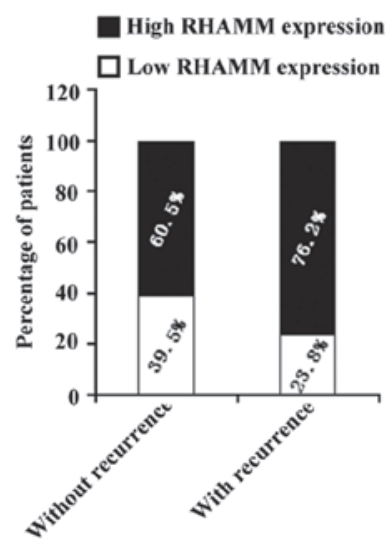

Figure 1. mRNA expression level of RHAMM in HCC tissues. (A) RT-qPCR analysis of RHAMM mRNA levels in 187 pairs of HCCs and ANLTs . For each specimen, the relative mRNA level of RHAMM was normalized to the level of $\beta$-actin. The line within each box represents the median $-\Delta C t$ value; the upper and lower edges of each box represent the 75th and 25th percentile, respectively; the upper and lower bars indicate the highest and lowest values determined ( $\mathrm{P}<0.001)$. RHAMM high: $2^{-\Delta \Delta C T}>1$ (or $-\Delta \Delta \mathrm{CT}>0$ ); RHAMM low: $2^{-\Delta \Delta C \mathrm{C}} \leq 1$ (or $\left.-\Delta \Delta \mathrm{CT} \leq 0\right)$ ). (B) The correlation between TNM stage and RHAMM mRNA expression in HCC. The percentage of high RHAMM expression patients with TNM stage III-IV was increased compared with TNM stage I-II. (C) The correlation between vascular invasion and RHAMM mRNA expression in HCC. The percentage of high RHAMM expression patients with vascular invasion was increased compared with those without vascular invasion. (D) The correlation between recurrence and RHAMM mRNA expression in HCC. The percentage of high RHAMM expression patients with recurrence was increased compared with those without recurrence. T, tumor; NL, normal liver; RHAMM, receptor for hyaluronic acid-mediated motility; HCC, hepatocellular carcinoma; ANLT, adjacent normal liver tissues; TNM, tumor-node-metastasis.

counterstained with Mayer's hematoxylin (Sigma-Aldrich), dehydrated and mounted.

Statistical analysis. The statistical analyses were performed using SPSS software, version 13.0 (SPSS, Inc., Chicago, IL, USA). Survival curves were generated using the Kaplan-Meier method and checked for statistical significance with the log-rank test. Qualitative variables were compared with the Pearson's Chi-square $\left(\chi^{2}\right)$ test, and the quantitative variables were analyzed by the independent Student's t-test. Chi-square test was used for correlation analysis. $\mathrm{P}<0.05$ was considered to indicate a statistically significant difference.

\section{Results}

RHAMM was upregulated in human HCC. The levels of RHAMM mRNA expression in the 187 pairs of human HCC and their ANLT were detected by RT-PCR. The results demonstrated that RHAMM expression was upregulated in $123(65.8 \%)$ of the $187 \mathrm{HCC}$ patients, while downregulated in 64 (34.2\%) cases $(\mathrm{P}<0.001)$ (Fig. 1A), compared with the corresponding ANLT. In addition, stratification analysis demonstrated that the percentage of high RHAMM expression in the patients whose TNM stage were III-IV was $73.3 \%$, compared with $57 \%$ in the patients with TNM stage I-II ( $\mathrm{P}=0.019$; Fig. 1B). The percentage of patients with vascular invasion that expressed high levels of RHAMM was $80.0 \%$, compared with $61.3 \%$ patients without vascular invasion $(\mathrm{P}=0.021$; Fig. $1 \mathrm{C})$. Furthermore, $76.2 \%$ of the patients with recurrence expressed high levels of RHAMM, whereas only $60.5 \%$ of patients without recurrence expressed high levels of RHAMM ( $\mathrm{P}=0.032$ Fig. 1D).

To further confirm the overexpression of RHAMM at the protein level, IHC was performed on 25 pairs of HCC and corresponding ANLT samples. The results demonstrated that RHAMM was overexpressed in $18(72 \%)$ of the $25 \mathrm{HCC}$ tissues compared with their ANLT $(\mathrm{P}=0.023)$, while RHAMM was overexpressed in only $10(40 \%)$ of the 25 ANLTs. In addition, the staining patterns indicated that RHAMM was mostly anchored in the cytoplasm and ECM (Fig. 2). Taken together, these data indicate that RHAMM expression levels were significantly upregulated in the HCC samples compared with the ANLT.

Correlation between the expression of RHAMM $M R N A$ and clinicopathological data in HCC tissues. In order to further determine the correlation between RHAMM expression and clinicopathological data in HCC, the RHAMM expression and clinicopathological data were examined (Table I). Notably, we found that RHAMM expression was significantly higher in HCC patients with TNM stage III-IV compared with those with TNM stage I-II $\left(\chi^{2}=5.476, \mathrm{P}=0.019\right.$; Table I). In addition, RHAMM expression was also much higher in HCC patients with the presence of vascular invasion $\left(\chi^{2}=5.327, \mathrm{P}=0.021\right)$ (Table $\left.\mathrm{I}\right)$ and recurrence $\left(\chi^{2}=4.578\right.$, $\mathrm{P}=0.032$ ) (Table I) compared with those without the presence of vascular invasion and recurrence. No significant association was observed between the RHAMM mRNA expression and age ( $\geq 55$ or $<55$ years), gender, family history, HBsAg, level of AFP ( $\geq 20 \mathrm{ng} / \mathrm{ml}$ or $<20 \mathrm{ng} / \mathrm{ml}$ ), tumor median size ( $\geq 5$ or $<5 \mathrm{~cm}$ ) and number, alcohol intake history, the presence of combined liver cirrhosis, distant metastasis, and LNM (all $\mathrm{P}>0.05$ ) (Table I). In conclusion, the upregulation of RHAMM is associated with TNM stage, vascular invasion and recurrence in $\mathrm{HCC}$.

RHAMM overexpression, clinical parameters were associated with disease-free and overall survival. After analyzing all the data, it was observed that high RHAMM mRNA expression levels, tumor size $\geq 5 \mathrm{~cm}$, multiple tumor number, TNM stage III-IV, and the presence of vascular invasion (all 

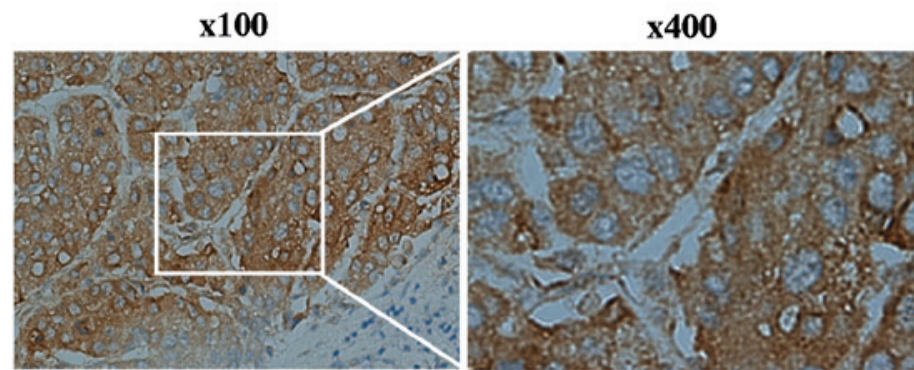

HCC
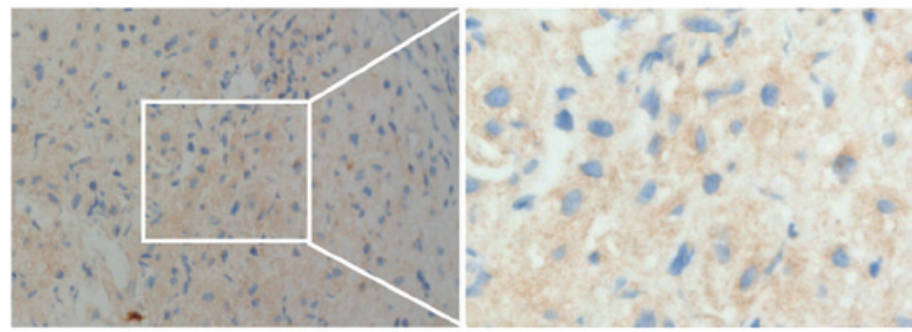

ANLT
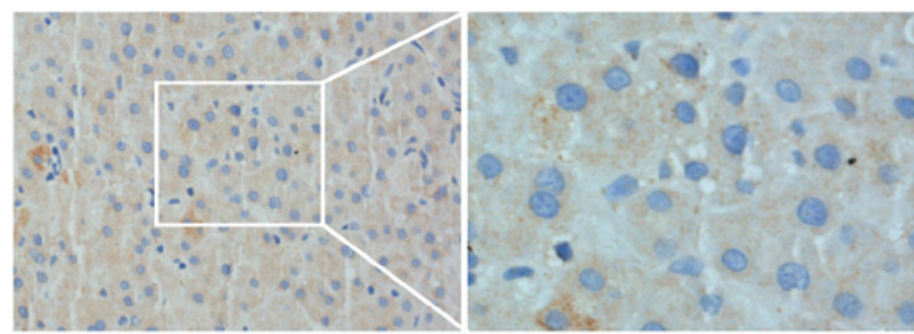

Normal Liver

Figure 2. Protein expression pattern of RHAMM in HCC tissues. Representative immunohistochemical RHAMM staining of a HCC specimen and its corresponding ANLT from a tissue array containing 25 pairs of HCC specimens. The nuclei were counterstained with hematoxylin. Original magnification: Left (x100) and right (x400) side (HCC, ANLT and normal liver). RHAMM, receptor for hyaluronic acid-mediated motility; HCC, hepatocellular carcinoma; ANLT, adjacent normal liver tissues.

A

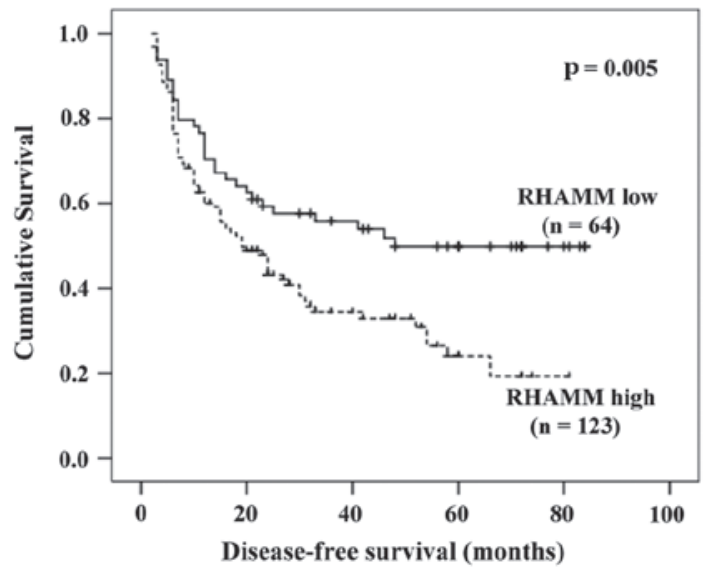

B

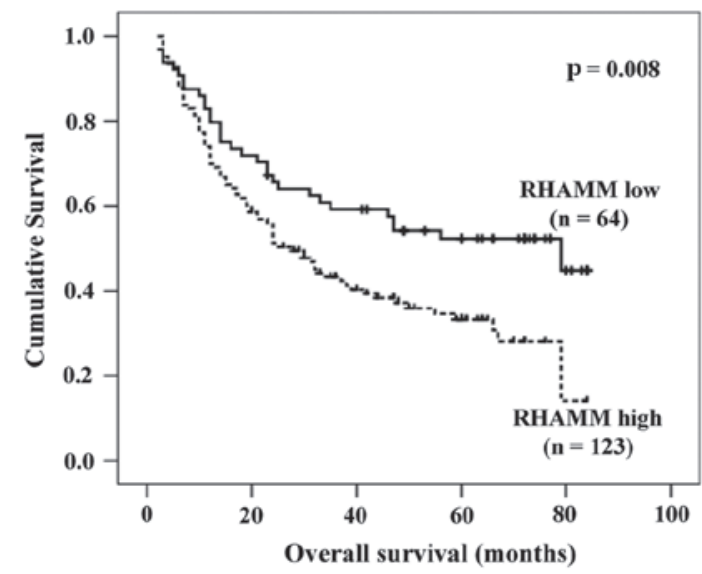

Figure 3. The association between RHAMM expression and disease-free/overall survival rate of patients with HCC. (A) Disease-free survival rate of patients with HCC. High expression of RHAMM was significantly associated with shorter disease-free survival rate $(\mathrm{P}=0.005)$. (B) Overall survival rate of patients with HCC. High expression of RHAMM was associated with shorter overall survival rate $(\mathrm{P}=0.008)$. RHAMM, receptor for hyaluronic acid-mediated motility; HCC, hepatocellular carcinoma.

$\mathrm{P}<0.01)$ were associated with shorter disease-free and overall survival rates (Table II). The presence of recurrence was also associated with shorter overall survival rates.

The median disease-free survival period for the 187 patients that expressed higher RHAMM levels was 32.67 months, with a 95\% confidence interval (CI) of 26.92-38.42 months; whereas, the disease-free survival period for patients that expressed lower RHAMM levels was 49.62 months, with a 95\% CI of 40.80-58.43 months. The results indicated that a higher RHAMM expression level was associated with shorter disease-free survival period $(\mathrm{P}=0.005)$ (Fig. 3A). The median overall survival time for all patients with higher RHAMM expression levels was 39.30 months, with a $95 \%$ CI of 33.63-44.97 months, whereas those of patients with 
Table I. Correlation between the clinicopathologic variables and RHAMM mRNA expression in HCC.

\begin{tabular}{|c|c|c|c|c|c|c|}
\hline \multirow{2}{*}{$\begin{array}{l}\text { Clinical } \\
\text { characteristics }\end{array}$} & \multirow[b]{2}{*}{ Variable } & \multirow[b]{2}{*}{ No. of patients } & \multicolumn{2}{|c|}{ RHAMM mRNA } & \multirow[b]{2}{*}{$\chi^{2}$} & \multirow[b]{2}{*}{ P-value } \\
\hline & & & Low n (\%) & High n (\%) & & \\
\hline \multirow[t]{2}{*}{ Age (years) } & $<55$ & 129 & $41(31.8)$ & $88(68.2)$ & 1.101 & 0.294 \\
\hline & $\geq 55$ & 58 & $23(39.7)$ & $35(60.3)$ & & \\
\hline \multirow[t]{2}{*}{ Gender } & Male & 160 & $56(35.0)$ & $104(65.0)$ & 0.296 & 0.586 \\
\hline & Female & 27 & $8(29.6)$ & $19(70.4)$ & & \\
\hline \multirow[t]{2}{*}{ Family history } & No & 158 & $53(33.5)$ & $105(66.5)$ & 0.209 & 0.647 \\
\hline & Yes & 29 & $11(37.9)$ & $18(62.1)$ & & \\
\hline \multirow[t]{2}{*}{ HBsAg } & Negative & 31 & $10(32.3)$ & $21(67.7)$ & 0.064 & 0.801 \\
\hline & Positive & 156 & $54(34.6)$ & $102(65.4)$ & & \\
\hline \multirow[t]{2}{*}{$\operatorname{AFP}(\mathrm{ng} / \mathrm{ml})$} & $<20$ & 54 & $14(25.9)$ & $40(74.1)$ & 2.323 & 0.127 \\
\hline & $\geq 20$ & 133 & $50(37.6)$ & $83(62.4)$ & & \\
\hline \multirow[t]{2}{*}{ Median size $(\mathrm{cm})$} & $<5$ & 69 & $25(36.2)$ & $44(63.8)$ & 0.196 & 0.658 \\
\hline & $\geq 5$ & 118 & $39(33.1)$ & $79(66.9)$ & & \\
\hline \multirow[t]{2}{*}{ Cirrhosis } & No & 15 & 4 (26.7) & $11(73.3)$ & 0.414 & 0.520 \\
\hline & Yes & 172 & $60(34.9)$ & $112(65.1)$ & & \\
\hline \multirow[t]{2}{*}{ Tumor no. } & Single & 128 & $42(32.8)$ & $86(67.2)$ & 0.359 & 0.549 \\
\hline & Multiple & 59 & $22(37.3)$ & $37(62.7)$ & & \\
\hline \multirow[t]{2}{*}{ Wine-drinking } & No & 92 & $28(30.4)$ & $64(69.6)$ & 1.155 & 0.282 \\
\hline & Yes & 95 & $36(37.9)$ & $59(62.1)$ & & \\
\hline \multirow[t]{2}{*}{ TNM stage } & I-II & 86 & $37(43.0)$ & $49(57.0)$ & 5.476 & 0.019 \\
\hline & III-IV & 101 & $27(26.7)$ & $74(73.3)$ & & \\
\hline \multirow[t]{2}{*}{ Vascular invasion } & No & 142 & $55(38.7)$ & $87(61.3)$ & 5.327 & 0.021 \\
\hline & Yes & 45 & $9(20.0)$ & $36(80.0)$ & & \\
\hline \multirow[t]{2}{*}{ Distant metastasis } & No & 169 & $57(33.7)$ & $112(66.3)$ & 0.192 & 0.661 \\
\hline & Yes & 18 & 7 (38.9) & $11(61.1)$ & & \\
\hline \multirow[t]{2}{*}{ LNM } & No & 173 & $60(34.7)$ & $113(65.3)$ & 0.215 & 0.643 \\
\hline & Yes & 14 & $4(28.6)$ & $10(71.4)$ & & \\
\hline \multirow[t]{2}{*}{ Recurrence } & No & 124 & $49(39.5)$ & $75(60.5)$ & 4.578 & 0.032 \\
\hline & Yes & 63 & $15(23.8)$ & $48(76.2)$ & & \\
\hline
\end{tabular}

Bold values indicate $\mathrm{P} \leq 0.05$ and is therefore statistically significant. HBsAg, hepatitis B surface antigen; TNM, tumor-node-metastasis; LNM, lymph node metastasis; AFP, $\alpha$-fetoprotein; HCC, hepatocellular carcinoma; RHAMM, receptor for hyaluronic acid-mediated motility.

lower RHAMM expression levels was 52.95 months, with a 95\% CI of 44.70-61.21 months. This result also indicated that increased RHAMM expression levels were associated with shorter overall survival rate $(\mathrm{P}=0.008)$ (Fig. 3B).

Overexpression of RHAMM was an independent predictor for disease-free and overall survival rates. In order to assess the prognostic significance of RHAMM expression and clinical parameters, a Cox multivariate proportional hazard model of independent predictors was established for disease-free and overall survival (Table III). Tumor size $\geq 5 \mathrm{~cm}$, multiple tumor number, TNM stage III-IV, the presence of vascular invasion, and overexpression of RHAMM were analyzed with Cox multivariate proportional hazard model for disease-free and overall survival, while recurrence was analyzed only used for overall survival.

The median of hazard ratio (HR) of RHAMM expression (high vs. low) was 1.574 with a $95 \%$ CI of $1.025-2.419(\mathrm{P}=0.038)$ for disease-free survival, while the median was 1.739 with a 95\% CI of 1.129-2.680 ( $\mathrm{P}=0.012)$ for overall survival, which indicates that high expression of RHAMM was an independent predictor for disease-free and overall survival. Furthermore, other factors including tumor size $\geq 5 \mathrm{~cm}$ (HR, 1.964; 95\% CI, 1.188-3.247; $\mathrm{P}=0.008)$, TNM stage III-IV (HR, 1.865; 95\% CI, 1.157-3.007; $\mathrm{P}=0.011)$ were also independent predictors for disease-free survival. On the other hand, tumor size $\geq 5 \mathrm{~cm}$ (HR, 1.738; 95\% CI, 1.054-2.867; P=0.030), III-IV of TNM stage (HR, 1.775; 95\% CI, 1.109-2.843; P=0.017), the presence of vascular invasion (HR, 1.599; 95\% CI, 1.053-2.427; $\mathrm{P}=0.027$ ), and recurrence (HR, 1.739; 95\% CI, 1.129-2.680; $\mathrm{P}<0.001)$ were independent predictors for overall survival.

\section{Discussion}

Despite improvements in HCC treatment, the clinical outcomes for HCC patients remain unsatisfactory, the reason for the poor 
Table II. Association between RHAMM expression, clinical parameters and disease-free/overall survival.

\begin{tabular}{|c|c|c|c|c|c|c|c|c|}
\hline \multirow{2}{*}{$\begin{array}{l}\text { Clinical } \\
\text { characteristics }\end{array}$} & \multirow[b]{2}{*}{ Category } & \multirow{2}{*}{$\begin{array}{l}\text { No. of } \\
\text { patients }\end{array}$} & \multicolumn{3}{|c|}{ Disease-free survival (months) } & \multicolumn{3}{|c|}{ Overall survival (months) } \\
\hline & & & Mean & $95 \% \mathrm{CI}$ & P-value & Mean & $95 \% \mathrm{CI}$ & P-value \\
\hline \multirow[t]{2}{*}{ RHAMM expression } & Low & 64 & 49.62 & $40.80-58.43$ & 0.005 & 52.95 & $44.70-61.21$ & 0.008 \\
\hline & High & 123 & 32.67 & 26.92-38.42 & & 39.30 & $33.63-44.97$ & \\
\hline \multirow[t]{2}{*}{ Age (years) } & $<55$ & 129 & 38.86 & $32.66-45.06$ & 0.560 & 43.71 & $37.91-49.51$ & 0.630 \\
\hline & $\geq 55$ & 58 & 41.75 & $32.85-50.64$ & & 45.76 & $37.37-54.16$ & \\
\hline \multirow[t]{2}{*}{ Gender } & Female & 160 & 38.26 & $32.85-43.67$ & 0.132 & 42.64 & $37.50-47.78$ & 0.080 \\
\hline & Male & 27 & 45.79 & $33.92-57.66$ & & 50.98 & $40.31-61.64$ & \\
\hline \multirow[t]{2}{*}{ Family history } & No & 158 & 39.23 & $33.69-44.76$ & 0.611 & 43.62 & $38.43-48.82$ & 0.459 \\
\hline & Yes & 29 & 43.42 & $30.42-56.42$ & & 48.52 & $36.23-60.81$ & \\
\hline \multirow[t]{2}{*}{ HBsAg } & Negative & 31 & 44.69 & $31.72-57.66$ & 0.501 & 48.73 & $36.96-60.50$ & 0.492 \\
\hline & Positive & 156 & 39.05 & $33.52-44.57$ & & 43.81 & $38.58-49.04$ & \\
\hline \multirow[t]{2}{*}{$\operatorname{AFP}(\mathrm{ng} / \mathrm{ml})$} & $<20$ & 54 & 37.82 & $28.62-47.01$ & 0.788 & 45.21 & $36.82-53.60$ & 0.882 \\
\hline & $\geq 20$ & 133 & 40.69 & $34.55-46.83$ & & 44.34 & $38.53-50.16$ & \\
\hline \multirow[t]{2}{*}{ Tumor size $(\mathrm{cm})$} & $<5$ & 69 & 58.02 & $50.23-65.80$ & $<0.001$ & 61.98 & $55.29-68.66$ & $<0.001$ \\
\hline & $\geq 5$ & 118 & 29.01 & 23.11-34.91 & & 33.76 & 28.06-39.45 & \\
\hline \multirow[t]{2}{*}{ Cirrhosis } & No & 15 & 38.91 & $20.49-57.33$ & 0.942 & 45.11 & $28.78-61.43$ & 0.777 \\
\hline & Yes & 172 & 39.68 & $34.35-45.00$ & & 44.28 & $39.27-49.28$ & \\
\hline \multirow[t]{2}{*}{ Tumor no. } & Single & 128 & 45.65 & $39.44-51.86$ & $<0.001$ & 50.24 & 44.57-55.92 & $<0.001$ \\
\hline & Multiple & 59 & 26.17 & $18.56-33.78$ & & 31.03 & $23.41-38.64$ & \\
\hline \multirow[t]{2}{*}{ Wine-drinking } & No & 92 & 45.13 & $37.33-52.94$ & 0.081 & 49.12 & $41.88-56.36$ & 0.081 \\
\hline & Yes & 95 & 35.45 & $28.85-42.05$ & & 40.55 & $34.29-46.81$ & \\
\hline \multirow[t]{2}{*}{ TNM stage } & I-II & 86 & 55.44 & $48.23-62.66$ & $<0.001$ & 59.72 & $53.34-66.10$ & $<0.001$ \\
\hline & III-IV & 101 & 25.82 & $19.99-31.66$ & & 31.44 & $25.51-37.38$ & \\
\hline \multirow[t]{2}{*}{ Vascular invasion } & No & 142 & 46.03 & $40.03-52.03$ & $<0.001$ & 50.66 & $45.17-56.15$ & $<0.001$ \\
\hline & Yes & 45 & 20.83 & $13.84-27.82$ & & 25.07 & $17.72-32.42$ & \\
\hline \multirow[t]{2}{*}{ Distant metastasis } & No & 169 & 40.90 & $35.49-46.30$ & 0.193 & 45.50 & $40.43-50.56$ & 0.191 \\
\hline & Yes & 18 & 27.07 & 15.04-39.09 & & 33.36 & $20.50-46.23$ & \\
\hline \multirow[t]{2}{*}{ LNM } & No & 173 & 40.88 & $35.52-46.24$ & 0.114 & 45.42 & $40.41-50.42$ & 0.137 \\
\hline & Yes & 14 & 26.19 & $12.85-39.54$ & & 31.91 & $17.63-46.18$ & \\
\hline \multirow[t]{2}{*}{ Recurrence } & No & 124 & & & & 37.54 & $31.60-43.49$ & $<0.001$ \\
\hline & Yes & 63 & & & & 56.76 & $50.17-63.34$ & \\
\hline
\end{tabular}

Bold values indicate $\mathrm{P} \leq 0.05$ and is therefore statistically significant. CI, confidence interval; HBsAg, hepatitis B surface antigen; AFP, $\alpha$-fetoprotein; TNM, tumor-node-metastasis; LNM, lymph node metastasis; RHAMM, receptor for hyaluronic acid-mediated motility.

prognosis of HCC include the difficulty in early diagnosis and the presence of tumor invasiveness, metastasis and recurrence (20). Although serum AFP level has been widely used for diagnosis of HCC, the sensitivity and specificity of AFP for HCC are limited (21). Therefore, it is urgent to identify novel potential biomarkers for early prognosis and monitoring of tumor recurrence, which is helpful for clinicians to select therapeutic strategies, so that the prognosis of HCC patients may be improved. The present study was designed to investigate RHAMM expression in HCC and its clinical significance.

The present study revealed that RHAMM mRNA expression was significantly upregulated $(65.78 \%, 123 / 187)$ in 187 pairs of primary HCC tissues compared with their paired ANLTs; this result indicates that upregulation of RHAMM is a common incident in $\mathrm{HCC}$, which is in accordance with the a previous study that demonstrated that RHAMM is upregulated in prostate cancer; furthermore, RHAMM proteins responding to HA stimulation led to activation of CD168/ROCK-signaling pathway, and the activation of HA-mediated CD168 signaling were associated with the cancer stage, Gleason's score, androgen-independent cell transformation and metastatic status of high-grade prostate cancer (14). Notably, p53 has been proposed to be able to repress expression of the RHAMM cell-surface and nuclear matrix protein (22), thus the expression of RHAMM, HA-mediated RHAMM signaling transduction and metastasis may be repressed by p53. However, the underlying mechanism of RHAMM upregulation in HCC remains unclear and future research based on this molecule are strongly recommended.

Notably, the results of the present study indicated that RHAMM upregulation is correlated with TNM stage, vascular invasion and recurrence, which demonstrated that the 
Table III. Cox multivariate proportional hazard model of independent predictors on disease-free and overall survival.

\begin{tabular}{lcr}
\hline Variable & HR $(95 \%$ CI $)$ & P-value \\
\hline $\begin{array}{l}\text { Disease-free survival } \\
\text { Tumor size, cm ( } \geq 5 \text { vs. <5) }\end{array}$ & $1.964(1.188-3.247)$ & $\mathbf{0 . 0 0 8}$ \\
Tumor no. & $1.326(0.877-2.005)$ & 0.181 \\
(multiple vs. single) & & \\
TNM stage (III-IV vs. I-II) & $1.865(1.157-3.007)$ & $\mathbf{0 . 0 1 1}$ \\
Vascular invasion (yes vs. no) & $1.375(0.890-2.123)$ & 0.151 \\
RHAMM expression & $1.574(1.025-2.419)$ & $\mathbf{0 . 0 3 8}$ \\
(high vs. low) & & \\
Overall survival & & \\
Tumor size, cm ( $\geq 5$ vs. <5) & $1.738(1.054-2.867)$ & $\mathbf{0 . 0 3 0}$ \\
Tumor no. (multiple vs single) & $1.356(0.922-2.106)$ & 0.125 \\
TNM stage (III-IV vs. I-II) & $1.775(1.109-2.843)$ & $\mathbf{0 . 0 1 7}$ \\
Vascular invasion (yes vs. no) & $1.599(1.053-2.427)$ & $\mathbf{0 . 0 2 7}$ \\
Recurrence (yes vs. no) & $2.194(1.412-3.409)$ & $<\mathbf{0 . 0 0 1}$ \\
RHAMM expression & $1.739(1.129-2.680)$ & $\mathbf{0 . 0 1 2}$ \\
(high vs. low) & & \\
\hline
\end{tabular}

Bold values indicate $\mathrm{P} \leq 0.05$ and is therefore statistically significant. CI, confidence interval; TNM, tumor-node-metastasis; HR, hazard ratio; RHAMM, receptor for hyaluronic acid-mediated motility.

upregulation of RHAMM contributes to tumor node invasion, venous invasion and recurrence in HCC. It has been demonstrated that RHAMM is associated with tubulin and actin cytoskeletal elements $(10,23)$, indicating that RHAMM may be important to the movement and reorganization of blastomeres during early embryonic development. RHAMM has also been reported to be associated with cytoskeletal interaction of mitochondria, thus, it may regulate mitochondrial motility and positioning (24), which is important for the physiological process of cytoplasmic maturation and the further development of mammalian oocytes (25). In addition, RHAMM regulates Ras signaling and is involved in breast cancer progression (26).The upregulation of RHAMM is therefore closely involved in regulating tumorigenesis, proliferation, tumor vascular invasion and node metastasis of HCC cells.

In addition, the present study demonstrated that upregulation of RHAMM is closely correlated with shorter disease-free and overall survival rates in HCC patients as an independent predictor. In HCC patients, disease-free survival is closely associated with recurrence due to tumorigenesis, proliferation, tumor cellular invasion, and metastasis of HCC cells. Furthermore, IHC analysis demonstrated that RHAMM protein level was higher in HCC tissues compared with their ANLTs, and the RHAMM protein was mostly anchored in the cytoplasm and ECM, which was in agreement with a study by Nedvetzki et al (27). RHAMM was the first discovered as cell-associated hyaladherin with multiple forms on the cell surface and in the cytoplasm. A previous study demonstrated that increased expression of RHAMM has been reported to be associated with rapid proliferation of tumor cells and reduced survival (9). RHAMM also forms complexes with CD44 (an HA receptor), and the complexes modulate intracellular signaling to promote invasion and metastasis of cancer cells (28). Furthermore, a study indicated that high preoperative serum HA levels predict poor prognosis in patients with HCC following hepatic resection (29). HA has been demonstrated to be involved in different cellular processes, including cellular invasion, tissue regeneration and angiogenesis (12,30,31). In addition, HA suppresses HGF-induced cell differentiation through RHAMM (32) and promotes cancer cell motility through CD44-EGFR (33). HA employs RHAMM to induce angiogenesis through recruitment of stromal cells $(34,35)$. In conclusion, upregulation of RHAMM may result in the poor clinical prognosis observed in HCC patients.

In conclusion, the present study provides evidence that high expression of RHAMM was associated with TNM stage, vascular invasion, and recurrence, demonstrating that it serves an important role in tumor pathogenesis, vascular invasion and recurrence of HCC. Furthermore, high RHAMM expression predicted poor prognosis of HCC by analyzing the association between expression of RHAMM and disease-free/overall survival of HCC patients following surgical resections. Further evidenceis required to determine the direct mechanisms of how RHAMM acts in regulating tumorigenesis, proliferation, cellular invasion, and metastasis in HCC cells. The results revealed an important role for RHAMM in HCC progression and prognosis, and it may be regarded as a promising therapeutic target for HCC.

\section{Acknowledgements}

The present study was supported in part by the National Natural Science Foundation of China (nos. 31370917, 30972797, 81430014, 81260328 and 81372163), the Natural Science Foundation of Guangxi (nos. 2014GXNSFDA118019 and 2013GXNSFCA019012), the Science and Technology Planning Project of Guangxi (no. 1140003B-79), the Lijiang Scholarship Foundation and the Science and Technology Planning Project of Guilin (no. 20110119-1-8), the Project of Collaborative Innovation Center of Universities in Guangxi, the Foundation of Distinguished Experts in Guangxi, and the Science and Technology Planning Project of Guilin (nos. 20140127-3 and 20100128-5).

\section{References}

1. Perz JF, Armstrong GL, Farrington LA, Hutin YJF and Bell BP: The contributions of hepatitis B virus and hepatitis $C$ virus infections to cirrhosis and primary liver cancer worldwide. J Hepatol 45: 529-538, 2006.

2. Siegel R, Naishadham D and Jemal A: Cancer statistics, 2013. CA Cancer J Clin 63: 11-30, 2013.

3. Ferenci P, Fried M, Labrecque D, Bruix J, Sherman M, Omata M, Heathcote J, Piratsivuth T, Kew M, Otegbayo JA, et al; World Gastroenterology Organisation Guidelines and Publications Committee: World Gastroenterology Organisation Guideline. Hepatocellular carcinoma (HCC): A global perspective. J Gastrointestin Liver Dis 19: 311-317, 2010.

4. Xiao WK, Chen D, Li SQ, Fu SJ, Peng BG and Liang LJ: Prognostic significance of neutrophil-lymphocyte ratio in hepatocellular carcinoma: A meta-analysis. BMC Cancer 4: 117-126, 2014.

5. Forner A, Llovet JM and Bruix J: Hepatocellular carcinoma. Lancet 379: 1245-1255, 2012.

6. Lin SL, Chang D and Ying SY: Hyaluronan stimulates transformation of androgen-independent prostate cancer. Carcinogenesis 28: 310-320, 2007.

7. Stojkovic M, Krebs O, Kölle S, et al: Developmental regulation of hyaluronan-binding protein (RHAMM/IHABP) expression in early bovine embryos. Biol Reprod 68: 60-66, 2003. 
8. Park D, Kim Y, Kim H, Kim K, Lee YS, Choe J, Hahn JH, Lee H, Jeon J, Choi C, et al: Hyaluronic acid promotes angiogenesis by inducing RHAMM-TGF $\beta$ receptor interaction via CD44-PKC $\delta$. Mol Cells 33: 563-574, 2012.

9. Shigeishi H, Higashikawa K and Takechi M: Role of receptor for hyaluronan-mediated motility (RHAMM) in human head and neck cancers. J Cancer Res Clin Oncol 140: 1629-1640, 2014

10. Assmann V, Jenkinson D, Marshall JF and Hart IR: The intracellular hyaluronan receptor RHAMM/IHABP interacts with microtubules and actin filaments. J Cell Sci 112: 3943-3954, 1999.

11. Koelzer VH, Huber B, Mele V, Iezzi G, Trippel M, Karamitopoulou E, Zlobec I, Lugli A: Expression of the hyaluronan-mediated motility receptor RHAMM in tumor budding cells identifies aggressive colorectal cancers. Hum Pathol: Jul 29, 2015 (Epub ahead of print). doi: 10.1016/j.humpath.2015.07.010.

12. SavaniRC,Cao G,Pooler PM,Zaman A,Zhou Zand DeLisser HM Differential involvement of the hyaluronan (HA) receptors CD44 and receptor for HA-mediated motility in endothelial cell function and angiogenesis. J Biol Chem 276: 36770-36778, 2001

13. Forteza R, Lieb T, Aoki T, Savani RC, Conner GE and Salathe M: Hyaluronan serves a novel role in airway mucosal host defense. FASEB J 15: 2179-2186, 2001.

14. Lin SL, Chang D, Chiang A and Ying SY: Androgen receptor regulates CD168 expression and signaling in prostate cancer. Carcinogenesis 29: 282-290, 2008.

15. Heldin P, Basu K, Olofsson B, Porsch H, Kozlova I and Kahata K: Deregulation of hyaluronan synthesis, degradation and binding promotes breast cancer. J Biochem 154: 395-408, 2013.

16. Ishigami S, Ueno $S$, Nishizono $Y$, Matsumoto $M$, Kurahara $H$, Arigami T, Uchikado Y, Setoyama T, Arima H, Yoshiaki K, et al: Prognostic impact of CD168 expression in gastric cancer. BMC Cancer 11: 106-110, 2011

17. Giannopoulos K, Li L, Bojarska-Junak A, Rolinski J, Dmoszynska A, Hus I, Greiner J, Renner C, Döhner H and Schmitt M: Expression of RHAMM/CD168 and other tumor-associated antigens in patients with B-cell chronic lymphocytic leukemia. Int J Oncol 29: 95-103, 2006.

18. Verslype C, Rosmorduc O and Rougier P; ESMO Guidelines Working Group: Hepatocellular carcinoma: ESMO-ESDO Clinical Practice Guidelines for diagnosis, treatment and follow-up. Ann Oncol 23 (Suppl 7): vii41-vii48, 2012.

19. Liao W, Liu W, Yuan Q, Liu X, Ou Y, He S, Yuan S, Qin L, Chen Q, Nong K, et al: Silencing of DLGAP5 by siRNA significantly inhibits the proliferation and invasion of hepatocellular carcinoma cells. PLOS One 8: e80789-e80797, 2013.

20. Zhang YC, Xu Z, Zhang TF and Wang YL: Circulating microRNAs as diagnostic and prognostic tools for hepatocellular carcinoma. World J Gastroenterol 21: 9853-9862, 2015.

21. Dong X, He H, Zhang W, Yu D, Wang X and Chen Y: Combination of serum RASSF1A methylation and AFP is a promising non-invasive biomarker for HCC patient with chronic HBV infection. Diagn Pathol 10: 133, 2015.

22. Godar S and Weinberg RA: Filling the mosaic of p53 actions: p53 represses RHAMM expression. Cell Cycle 7: 3479-3480, 2008.

23. Assmann V, Marshall JF, Fieber C, Hofmann M and Hart IR The human hyaluronan receptor RHAMM is expressed as an intracellular protein in breast cancer cells. J Cell Sci 111: $1685-1694,1998$
24. Lynn BD, Turley EA and Nagy JI: Subcellular distribution, calmodulin interaction, and mitochondrial association of the hyaluronan-binding protein RHAMM in rat brain. J Neurosci Res 65: 6-16, 2001.

25. Stojkovic M, Machado SA, Stojkovic P, Zakhartchenko V, Hutzler P, Gonçalves PB and Wolf E: Mitochondrial distribution and adenosine triphosphate content of bovine oocytes before and after in vitro maturation: Correlation with morphological criteria and developmental capacity after in vitro fertilization and culture. Biol Reprod 64: 904-909, 2001.

26. Wang C, Thor AD, Moore DH II, Zhao Y, Kerschmann R, Stern R, Watson PH and Turley EA: The overexpression of RHAMM, a hyaluronan-binding protein that regulates ras signaling, correlates with overexpression of mitogen-activated protein kinase and is a significant parameter in breast cancer progression. Clin Cancer Res 4: 567-576, 1998.

27. Nedvetzki S, Gonen E, Assayag N, Reich R, Williams RO, Thurmond RL, Huang JF, Neudecker BA, Wang FS, Turley EA, et al: RHAMM, a receptor for hyaluronan-mediated motility, compensates for CD44 in inflamed CD44-knockout mice: A different interpretation of redundancy. Proc Natl Acad Sci USA 101: 18081-18086, 2004.

28. Li H, Guo L, Li JW, Liu N, Qi R and Liu J: Expression of hyaluronan receptors CD44 and RHAMM in stomach cancers: relevance with tumor progression. Int J Oncol 17: 927-932, 2000

29. Mima K, Beppu T, Ishiko T, Chikamoto A, Nakagawa S, Hayashi H, Watanabe M, Sakamaki K and Baba H: Preoperative serum hyaluronic acid level as a prognostic factor in patients undergoing hepatic resection for hepatocellular carcinoma. Br J Surg 101: 269-276, 2014.

30. Bourguignon LY, Gilad E, Peyrollier K, Brightman A and Swanson RA: Hyaluronan-CD44 interaction stimulates Rac1 signaling and PKN gamma kinase activation leading to cytoskeleton function and cell migration in astrocytes. J Neurochem 101: 1002-1017, 2007.

31. Contreras EG, Gaete M, Sánchez N, Carrasco H and Larraín J: Early requirement of Hyaluronan for tail regeneration in Xenopus tadpoles. Development 136: 2987-2996, 2009.

32. Washio A, Kitamura C, Jimi E, Terashita M and Nishihara T: Mechanisms involved in suppression of NGF-induced neuronal differentiation of PC12 cells by hyaluronic acid. Exp Cell Res 315: 3036-3043, 2009.

33. Kim Y, Lee YS, Choe J, Lee H, Kim YM and Jeoung D: CD44-epidermal growth factor receptor interaction mediates hyaluronic acid-promoted cell motility by activating protein kinase $\mathrm{C}$ signaling involving Akt, Racl, Phox, reactive oxygen species, focal adhesion kinase, and MMP-2. J Biol Chem 283: 22513-22528, 2008

34. Koyama H, Hibi T, Isogai Z, Yoneda M, Fujimori M, Amano J, Kawakubo M, Kannagi R, Kimata K, Taniguchi S, et al: Hyperproduction of hyaluronan in neu-induced mammary tumor accelerates angiogenesis through stromal cell recruitment: Possible involvement of versican/PG-M. Am J Pathol 170: 1086-1099, 2007.

35. Golshani R, Lopez L, Estrella V, Kramer M, Iida N and Lokeshwar VB: Hyaluronic acid synthase-1 expression regulates bladder cancer growth, invasion, and angiogenesis through CD44. Cancer Res 68: 483-491, 2008. 